\title{
Psychiatric clinics in residential homes for the elderly
}

\author{
Graham A. Jackson and Donald Lyons
}

\begin{abstract}
We have evaluated the eflects of providing a 'roving' poychiatiric clinic to local cuthortiy realdential homes for the elderty. The clinic was well recelved by the stafl in the homes, reduced the need for urgent domicillary consultations and hospltal admission and appeared to be highly cost-effective.
\end{abstract}

The proportion of elderly people with dementia in residential homes for the elderly is on the increase. Mann et al (1984) found that only 33\% of residents in residential homes for the elderly in a London borough were free from dementia. In a follow-up study (Ames et al, 1988), this proportion had fallen to $23 \%$. Other studies confirm this trend. Harrison et al (1990) rated $87 \%$ of residential home residents as having moderate to severe dementia, while Neville et al (1995) found that $53 \%$ had severe cognittve impairment and $82 \%$ showed some degree of dementia. They commented on the need for more frequent and specialised psychiatric, medical and nursing assessment of people in residential care.

We describe one way of meeting this need. For two years a 'roving clinic' was provided to Local Authority residential homes as well as specialist dementia day centres under Local Authority control.

\section{The study}

In the South East Glasgow catchment area, there are four Local Authority residential homes, two of which have specific dementla day care. One home has a specific 10-place residential dementia unit. In addition, there is one specialist Local Authority dementia day care and respite care centre. In total, there are 192 residential places, 17 of which are designated respite places. One hundred and fifty-seven clients are catered for in day care. Estimates obtained from the officers in charge suggested that about $60 \%$ of permanent places are occupied by elderly people with mental illness, mostly dementia. The vast majority of respite clients and almost all the day attenders suffer from dementia. Prior to 1993, input was provided by the psychiatric services in the form of visits by the community psychiatric nurses, domiciliary visits by the consultant and a regular and continuing need for hospital admissions for assessment and treatment.

Between 1993 and 1994, a roving clinic was established, visiting each of the five locations. Allowing for holidays, this resulted in a clinic approximately every six weeks in each location. The residential home being visited would know the date of the next clinic and would be contacted a week in advance for a list of residents requiring psychiatric review. Referral was directly by residential care staff who contacted the general practitioner (GP) for approval prior to the patient being seen by us. As far as we are aware, no GP objected. A regular afternoon session was set aside and a room made available in each home for the afternoon. Prior to seeing the patient, we would receive a statement of the problem (or progress) from the patient's key worker. Recommendations for further treatment would then be made to the patient's GP and the officer in charge of the residential home would recetve copies of all reports.

For the first year, this clinic was performed by the consultant (DL) but was delegated to the staff grade doctor (GJ) on his appointment in February 1994. We felt it important to evaluate the expenditure of one session a week of medical time in this way, both in terms of cost-effectiveness and assessment of the views of others on the quality of the service recetved.

The following figures were collected:

(1) number of clinic sessions and people seen (new and return)

(2) use of in-patient beds for assessment of people referred from residential homes

(3) requests for domiciliary visits to residential homes

(4) satisfaction levels among senior care staff as regards the service

(5) costings for income to and expenditure by the Trust.

Because of secretarial shortage, there was a spell when clinics were not being recorded and we have therefore based the costings on $\mathbf{5 8}$ clinic sessions for which figures were available over the twoyear-period. In assessing the satisfaction of senior care staff, we asked them to fill in a 
satisfaction rating questionnaire as well as provide their own comments.

\section{Findings}

Table 1 shows the number of people seen, on average, at the roving clinic with costings per session. The actual number of people seen at one clinic visit varied from 1 to 8 . The costs on which Trust income per session are based come from proposed charges for out-patient attendances for the financial year 1996/97.

Table 2 reveals a marked drop in the requests for domiciliary visits to residential homes. This had been on the increase, as had admissions, until 1993. Domiciliary visits to nursing homes outwith the roving clinic rose slightly over this time. There was a fall in admissions from residential homes, most dramatic during 1994.

We obtained satisfaction ratings from the senior care staff in the homes on aspects of the service recetved. On a scale of 1 to 4 , where $1=$ excellent benefit, 2 =good benefit, $3=$ no benefit, and $4=$ detrimental effects, the average satisfaction level was as follows:

Access to psychiatric advice Contact with psychiatrist outwith the clinic 1.4 Improved management of residents Education of staff

Managing residents outwith hospital

Feedback from clinic visits

Communication with local GP

Overall value of clinic

Table 1. Roving clinic attendances (with costs)

\begin{tabular}{llll}
\hline & 1993 & 1994 & Total \\
\hline Clinic sessions & 24 & 34 & 58 \\
New patients & 40 & 29 & 69 \\
Retum patients & 53 & 137 & 190 \\
New patients per session & 1.67 & 0.85 & 1.19 \\
Retum patients per session & 2.22 & 4.03 & 3.27 \\
Expenditure per session' & $\$ 180$ & $\$ 93$ & - \\
lncome per session $^{2}$ & $£ 282$ & $\$ 303$ & - \\
Net income per session & $£ 102$ & $\$ 210$ & - \\
\hline
\end{tabular}

1. Based on cost of medical time+33\% addition for administrative costs

2. Based on price of $\$ 96.00$ for a new attendance and $\$ 55.00$ for a return attendance

Table 2. Domicillary visits to, and admissions from residential homes

\begin{tabular}{llc}
\hline & Domiciliary visits & Admissions \\
\hline 1991 & 16 & 5 \\
1992 & 29 & 22 \\
1993 & 6 & 19 \\
1994 & 3 & 5 \\
\hline
\end{tabular}

\section{Comment}

The service we describe meets the challenge of Neville et al (1985) in fulfilling the needs of elderly mentally ill people in residential homes. In addition, the clinic was cost-effective, not just in terms of generating income by seeing a greater number of patients but by reducing expenditure on domiciliary visits and on in-patient care. The clinic was also available to day attenders which allowed more people access to specialist services than had hitherto been the case. The clinic was well received by senior care staff and helped to cement good relationships between health care and social agencies. Staff made comments about it being easier to admit people to hospital when necessary despite the clear drop in admissions from residential homes in the two years in which the clinic was operating. From Table 2, it seems that most domiciliary visits to residential homes resulted in hospital admission and were probably crises. It seems likely that the 'roving clinic' resulted in planned admissions and helped to avoid crises.

The majority of people seen at the clinic suffered from dementia. In view of the high prevalence of depressive disorder among residential home residents, for example the rate of $38 \%$ quoted by Mann et al (1984), we perhaps did not see enough people with depression. This may be a target area for further development of the service. Also, limitations on time meant that the service could only be extended to Local Authority home residents and was not available to residents of private residential and nursing homes. The high prevalence of behaviour disturbance in nursing homes and high use of neuroleptic medication (McGrath \& Jackson, 1996) indicate that nursing homes would benefit from a service along similar lines.

\section{Conclusions}

The South East Glasgow roving clinic was a valuable addition to the care of the elderly mentally ill which was cost-effective and well received by residential home staff. We feel that other service providers may wish to adopt a similar model.

\section{References}

Ames, D., Ashby, D., MANn, A. H., et al (1988) Psychiatric lliness in elderly residents of Part 111 homes in one London borough: prognosis and review. Age and Ageing. 17. 249-256.

HARRISON, R. SAVLA, N. \& KAFETZ, K. (1990) Dementia depression and physical disability in a London borough: a survey of elderly people in and out of residential care and implications for future developments. Age and Ageing, 18, 97-103. 
MCGRATH, A. \& JACKSON, G. A. (1996) Survey of neuroleptic prescribing in residents of nursing homes in Glasgow. Britlsh Medical Journal, 312, 611.

MANN, A. H., GRAHAM, N. \& ASHBY, B. (1984) Psychiatric illness in residential homes for the elderly: a survey in one London borough. Age and Ageing, 13, 257-265.

NeVILLE, P. G., BROOKE, A., BROOKE, S., et al (1995) Time for change: psychiatric morbidity in residential homes for the elderly. International Journal of Geriatric Psychiatry. 10, 561-568.
Graham A. Jackson, Senior Registrar in Psychiatry, Hairmyres Hospital, East Kilbride; and ${ }^{*}$ Donald Lyons, Clinical Director, Elderly Mental Health Services, Leverndale Hospital, 510 Crookston Road, Glasgow G53 7TU

\title{
Comparison of psychogeriatric domiciliary visit service between urban and suburban sectors
}

\author{
Arun K. Jha and Robert Lawrence
}

\begin{abstract}
This study presents a comparison between the domIcillary consultation services in urban and suburban sectors of the Croydon Health District. Urban general practitioners requested less domicillary vistis (DV) and tended to be less satistied with this service than their suburban counterparts. Sociodemographic factors such as population density and multi-ethnicity in the urban sector may be responsible for a smaller referral rate and the degree of satistaction with the psychogeriatric DV service in Croydon.
\end{abstract}

Despite recent criticism and declining trend, the domiciliary visit (DV) remains a major component of a modern psychogeriatric service (Donaldson \& Hill, 1991; Forsythe, 1991). Few studies have examined the DV service in geriatric psychiatry (e.g. Hardy-Thompson, 1992; Orrell et al, 1992), and none has looked at the service in different types of communities.

A higher number of DV requests from the southern (suburban) sector of Croydon prompted us to investigate the difference between the North (urban) and the South. This study is an attempt to evaluate and compare the DV service in urban and suburban halves of Croydon by investigating general practitioners' (GP) views of the service.

Croydon is the largest of the London boroughs with a population of 320000 people, of whom $43000(13.8 \%)$ are aged over 65 . Nearly $95 \%$ of them live independently in their own homes (Health in Croydon, 1994-95). Each half of the health district has a nearly equal population, 21000 in the North and 22000 in the South, and each has a consultant-led elderly community mental health service.

Croydon has a higher proportion of ethnic minority communities than the rest of England and Wales, with $19 \%$ of black, and $24.6 \%$ of Asian ethnic groups, and 6\% are elderly people (Health in Croydon, 1994-95). Its two halves are different in their socioeconomic and demographic characteristics. The northern-half is part of south-east London and shares its urban characteristics. It is much more densely populated than South Croydon which is suburban, containing a higher proportion of private nursing homes and more elderly people requiring special care.

\section{The study}

To obtain the vlews of GPs regarding requests for DVs for patients over 65, a questionnaire was designed on the basis of a previous study (Orrell et al, 1992). This was sent to all 170 GPs in the Croydon Health District, 97 in the North and 73 in the South. The items (Table 1) related to various aspects of the DV service on a two- to five-point scale. Data were analysed using the SPSS statistical package. 